\title{
A fragrância plural do sufismo: Ibn'Arabi e a abertura inter-religiosa
}

Faustino Teixeira

\section{Resumo}

Observa-se na tradição mística do islã uma singular abertura ao pluralismo religioso. Desde o século IX temos exemplos significativos de pensadores, como al-Hallaj, que sinalizavam que as diversas religiões "são ramificações de um Princípio único". Nas trilhas abertas pelo livro do Alcorão, entendiam que a luz do Mistério sempre maior refratava-se nas várias religiões, sinalizando a vitalidade de uma onipresença. Um dos sistematizadores desta perspectiva de abertura foi o místico sufi andaluz Ibn'Arabi (11651240), para o qual a diversidade religiosa é um dos substantivos sinais da Misericórdia de Deus.

Palavras-chave: Islã, Mística, Pluralismo Religioso, Sufismo.

\begin{abstract}
It is observed that on the mystical tradition of Islam a singular openness to religious pluralism. Since the ninth century we have been significant examples of thinkers such as al-Hallaj, who signaled that the various religions "are branches of a single Principle". Trails in the book of Koran, they understood that the light of Mystery is always more refracted in various religions,
\end{abstract}


suggesting the vitality of the one omnipresence. One of the organizers of this perspective was the Mystic Andalusian Sufi Ibn'Arabi (1165-1240), for which the religious diversity is one of the substantive signs of God's Mercy.

Kaywords: Islam, Mysticism, Religious Pluralism, Sufism.

\section{Introdução}

O sufismo é o nome mais recorrente para designar a experiência mística do islã, traduzindo uma "dimensão interior" muitas vezes desconhecida ou desapercebida da tradição islâmica. O sufismo (tasawwuf) remonta às origens do islã, e durante todo o seu desenvolvimento esteve radicalmente ligado às referências canônicas dessa tradição religiosa, em particular ao livro do Alcorão e ao profeta Muhammad. Não se descarta, é verdade, todo o processo de hibridação que enriqueceu o vocabulário místico do islã, mas o núcleo do sufismo guarda uma singularidade original, pontuada pelo referencial corânico ${ }^{1}$. A mística dos sufis vem marcada por um essencial traço muçulmano: "todas as suas doutrinas, gestos, usos e práticas baseiam-se sobre uma particular interpretação do Alcorão e da tradição profética"2.

Há na tradição mística sufi uma predileção pela interioridade, pela contemplação e o crescimento espiritual. Prevalece o toque singular do esoterismo e não do exoterismo, entendido como exterioridade da fé e apego ao seu legalismo. A linguagem das alusões ganha ali um destaque particular:

"Enquanto o exotérico segue somente a rota conhecida, traçada no mapa, o iniciado explora, além disso, a dimensão da experiência interna e, em sua peregrinação pela senda do conhecimento, rastreia os atalhos da inspiração, seguindo os indícios que encontra em seu passo, sem se deter mais do que o necessário nas sucessivas pousadas e paisagens que, como degraus de sua ascensão, vai deixando para trás”3.

\footnotetext{
${ }^{1}$ Para essa reflexão cf. Louis MASSIGNON. Essais sur les origines du lexique technique de la mystique musulmane. Paris: Cerf, 1999. Segundo Massignon, "é do Alcorão, constantemente recitado, meditado, praticado, que procede o misticismo islâmico, em sua origem e desenvolvimento": Ibidem, p. 104.

${ }^{2}$ Marijan MOLÉ. I mistici musulmani. Milano: Adelphi, 1992, p. 14.

${ }^{3}$ Pablo BENEITO ARIAS. Esoterismo diante do exoterismo: a linguagem das alusões no sufismo segundo Ibn'Arabî de Múrcia. In: Faustino TEIXEIRA (Org.). No limiar do mistério. Mística e religião. São Paulo: Paulinas, 2004, p. 376.
} 
Há no plano teológico, uma ênfase na misericórdia, gentileza e beleza de Deus, que atuam como forças muito mais fundamentais do que os traços de sua majestade, severidade ou cólera. As diversas narrativas sufis indicam que a maior proximidade ao mundo espiritual faculta a percepção cristalina da gratuidade e misericórdia de Deus, que escapam ao olhar rasteiro de quem se fixa no domínio das coisas superficiais. Na medida em que se avança na interiorização, percebe-se com nitidez o fluir incessante da misericórdia de Deus que abraça todas as coisas ${ }^{4}$.

Ibn'Arabî de Múrcia talvez seja um dos mais significativos e complexos pensadores da tradição sufi. É conhecido em árabe como al-shaykh al-akbar (o maior mestre/instrutor). Autor de mais de 350 obras, marcadas por grande criatividade. Nasceu no sudeste da Espanha (Múrcia) em 1165 e morreu aos 75 anos em Damasco, no ano de 1240. O traço peculiar de suas obras é a universalidade, amplitude e abertura. Dentre as mais conhecidas, podem-se destacar: Al-futuhat al-makkiyya (As revelações de Meca); Fusus al-Hikam (Os engastes da sabedoria); Tarjuman al-Ashwák (O intérprete dos ardentes desejos) e Kitâb al-tajalliyât (O livro das teofanias).

Em linha de sintonia com al-Hallâj (858-922), Ibn'Arabî foi um dos grandes defensores do pluralismo religioso, situando a diversidade religiosa como um dos substantivos sinais da Misericórdia de Deus. Reverberando o traço universalista da mensagem sufi, ele busca mostrar que esta diversidade "foi estabelecida por obra da sabedoria e compaixão divinas". Não há tensão entre a unidade requerida da wujū $d^{6}$ absoluta e não delimitada de Deus e a multiplicidade da realidade. Na verdade, essa multiplicidade é acolhida como um valor, pois tem suas raízes em Deus.

Para Ibn'Arabî, todo o cosmo vem percebido como lugar de manifestação de Deus. A seu ver, todas as coisas existentes procedem de Deus e sinalizam sua Presença no tempo. Não há nada no mundo que Dele esteja desligado. Não há para ele uma subsistência autônoma das entidades, mas estas existem enquanto particularizações e determinações de um Absoluto Indeterminado. $\mathrm{O}$

\footnotetext{
${ }^{4}$ William C. CHITTICK. Il sufismo. Torino: Einaudi, 2009, pp. 15-18.

${ }^{5}$ William C. CHITTICK. Mundos imaginales. Ibn al-Arabî y la diversidad de las creencias. Sevilla: Alquitara, 2003, p. 7. E também pp. 5 e 8-10.

${ }^{6}$ A expressão wujūd pode ser traduzida como "ser" ou "existência". Há na tradição sufi uma clássica expressão, que vem, em geral, associada ao pensamento de Ibn' Arabî, ainda que ele não a tenha diretamente utilizado: wahdat al- wujūd, ou seja, a "unidade do Ser" ou "unidade da existência". Ver a respeito: William C. CHITTICK. Mundos imaginales. Ibn al-Arabî y la diversidad de las creencias, pp. 29-57.
} 
que confere realidade às coisas é o seu nexo intrínseco e fundamental com o seu Fundamento metafísico original ${ }^{7}$. Em sua obra Al-futuhat assinala:

\begin{abstract}
“(...) Deus favoreceu-me com a Face do Real em tudo. Para mim, a meus olhos, não há nada existente neste mundo em que eu não testemunhe a realidade essencial de Deus, e desse modo glorifico-O aqui. Assim não descartamos (ou:condenamos) absolutamente nada neste mundo da existência"s.
\end{abstract}

Essa reflexão liga-se à idéia de wahdat al wujūd (unidade da existência ou unicidade do ser), atribuída a Ibn 'Arabi (1165-1240), com influxo importante na tradição mística islâmica posterior. Trata-se de uma doutrina complexa e que não pode ser reduzida a uma visão monista. A afirmação da unidade da existência não indica em momento algum que os objetos da criação são Deus, ou que Deus reside substancialmente nas coisas. A doutrina leva a um raciocínio bem mais matizado e complexo. Traduz, na verdade, uma compreensão básica, de que "todas as coisas estão intimamente interrelacionadas por meio de suas raízes comuns na Divina Realidade" ". Com base na reflexão de Willian Chittick, pode-se dizer que:

\begin{abstract}
"Ibn 'Arabî expressa sua posição sobre a realidade das criaturas mais sucintamente com a frase huwala huwa, 'Ele/não Ele'. Ele entende que isto significa que tudo revela a Deus, porque todas as coisas ganham sua existência e seus atributos da wujūd de Deus e dos atributos dele, e que tudo também encobre a Deus, porque nada é realmente Ele a não ser Ele, enquanto que cada coisa é realmente ela mesma, criada por Deus precisamente para ser ela mesma e nada mais" ${ }^{\prime 10}$.
\end{abstract}

\footnotetext{
${ }^{7}$ William C.CHITTICK. Il sufismo. Torino: Einaudi, 2009, pp. 109-110; Toshihiko IZUTSU. Unicità dell'esistenza e creazione perpetua nella mistica islamica. Genova: Marietti, 1991, p. 43.

${ }^{8}$ Apud Stephen HIRTENSTEIN. O compassivo ilimitado. A vida e o pensamento espiritual de Ibn'Arabi. Rio de Janeiro: Fissus, 2006, p. 99.

${ }^{9}$ William CHITTICK. Mundos imaginales, p. 227. Ibn'Arabi recorre com freqüência ao verso corânico que sinaliza a presença criadora de Deus em cada coisa existente (Corão 20,50).

${ }^{10}$ William CHITTICK. Ibn'Arabi e Rûmî. Numen, v. 8, n. 1, 2005, p. 29. O substantivo Deus vem designado em árabe como Allah e em persa como khudâ. Haqq (o Verdadeiro, o Real) é também uma expressão corânica para designar o Mistério de Deus: "Como nome divino, a palavra significa que não há nada real, verdadeiro, correto, próprio e apropriado no sentido pleno destas palavras além de Deus mesmo. Somente Deus é verdadeiramente Haqq em cada sentido da palavra": William CHITTICK. Ibn' Arabi e Rûmî, p. 31. A expressão al-Haqq, também de ampla utilização no vocabulário do místico sufi al-Hallaj, traduz a "pura substância divina", a "subs-
} 
$\mathrm{Na}$ tradição mística do sufismo, e em particular na obra de Ibn 'Arabi, o mistério de Deus - wujūd ilimitado -, pode ser captado através de dois termos chaves presentes na terminologia teológica do islã tradicional: tanzīh e tašbīh. O primeiro termo, tanzīh, vem do verbo árabe nazzaha, que significa "proteger algo de qualquer contaminação". O termo vem utilizado para assinalar a transcendência e incomparabilidade essencial de Deus: sua distância com respeito à toda criatura. O segundo termo, tašbīh, provém do verbo šabbaha, que significa "fazer ou considerar algo similar a outra coisa". É um termo que expressa a proximidade de Deus com a sua criação, sua comparabilidade com as coisas existentes. Deus vem, assim, expresso em sua dupla polaridade: é por um lado radicalmente transcendente, mas também imanente ${ }^{11}$. Deus é simultaneamente majestoso (Jalăl) e belo (Jamāl). Ou também nas expressões consagradas de Rudolf Otto, Tremendum e Fascinans.

A aproximação de Deus, entendido como o Real (al-Haqq), não pode acontecer quando se privilegia exclusivamente um destes pólos. Ibn 'Arabi serviu-se da história corânica de Noé e os idólatras para mostrar que não se pode captar o Real quando se exclusiviza seja o seu lado transcendente, seja o seu lado imanente. Este mistério é simultaneamente transcendente e imanente. Tanto os "idólatras" como Noé equivocaram-se em sua aproximação deste Mistério. Os "idólatras" por vincular o Real com os objetos físicos de sua adoração (imanentização) e Noé por vincular o Real com o transcendente. Os primeiros equivocaram-se por desconsiderar a dimensão transcendente do Real, e o segundo por negar sua dimensão imanente ${ }^{12}$. Como sublinhou Michael Sells,

"Dado que o real é infinito, não pode ser limitado aos confins de uma única crença: o deus da crença não é o Deus verdadeiro, mas somente um ídolo intelectual. A tragédia é que de fato o real se manifesta verdadeiramente nessa imagem, mas ao limitar o real a essa imagem particular e ao negar suas outras manifestações, terminamos por negar o real em sua infinitude"13.

tância criadora", distinguindo-se da criação, al-Khalq: Louis MASSIGNON. Écrits memorables 1. Paris: Robert Lafont, 2009, p. 446.

${ }^{11}$ Toshihiko IZUTZU. Sufismo y taoísmo. 2 ed. Madrid: Siruella, 2004, pp. 63-83 (Ibn 'Arabi vol. 1). Ver também a boa tradução italiana, organizada por Alberto de Luca: Sufismo e taoísmo. Milano: Mimesis, 2010, pp. 71-91.

${ }^{12}$ Ibn 'ARABI. Le livre des chatons des sagesse. Tome premier. Beyrout: Al-Bouraq, 1997, pp. 115-145 (Le chaton d'une sagesse transcendante dans un verbe de Nûh - Noé).

${ }^{13}$ Michael SELLS. Tres seguidores de la religión del amor: Nizām, Ibn 'Arabi y Marguerite Porete. In: Pablo BENEITO \& Lorenzo PIERA \& Juan José BARCENILLA (Eds). Mujeres de luz. Madrid: Trotta, 2001, p. 141. 
A doutrina de wahdat al wujūd requer uma compreensão do processo contínuo das manifestações do Real nas formas concretas. Este processo vem nomeado como tajalli e constitui um eixo referencial do pensamento de Ibn 'Arabi. É correto, de um lado, compreender o mundo fenomênico como expressão do Real, e o verdadeiro conhecedor é capaz de desocultar a presença subjacente do Real nas manifestações existenciadas. Mas isto não significa conceber o mundo fenomênico de forma autônoma e subsistente. $\mathrm{Na}$ visão de Ibn 'Arabi, a única verdadeira existência pertence ao Um (Real). Mas esse Um torna-se perceptível em todas as manifestações. As coisas ganham sua existência como lugares de manifestação e reflexos desta Unidade primordial. O mundo é visto, assim, de forma positiva, na medida em que ele reflete as manifestações das insondáveis possibilidades do Ser de Deus.

Relacionando essa reflexão com a doutrina de wahdat al-wujūd, assinala-se que cada coisa existente insere-se na auto-revelação particular da wujūd ilimitada. As coisas são como as cores existenciadas pelo prisma da infinita possibilidade da wujūd. Tudo o que existe no universo, incluindo a diversidade das crenças, "são palavras articuladas no Hálito do Todo Misericordioso"14. Todas as coisas existentes estão misteriosamente interrelacionadas por raízes que procedem da Divina Realidade.

Segundo Ibn'Arabî, Deus manifesta-se no tempo a cada segundo e de forma sempre renovada. As teofanias sucedem-se ininterruptamente e se irradiam sobre o mundo, sempre de forma novidadeira. Há um profundo nexo de amor que vincula Deus com suas criaturas. Há uma proximidade singular que não pode ser abafada ou excluída. O humano vem unido a Deus por laços ainda mais estreitos do que a própria vida e a veia jugular. Em belo poema que abre o capítulo do Fusus dedicado a Hûd ${ }^{15}$, o Sheikh assinala:

"A Via Reta pertence a Deus (Allah).

Manifesta-se em tudo, não se oculta.

Está presente nos pequenos e grandes,

\footnotetext{
${ }^{14}$ William C. CHITTICK. Mundos imaginales, p. 259.

${ }^{15}$ A sura de numero 11 do Alcorão vem dedicada a Hûd. Trata-se de um dos três profetas árabes anteriores a Muhammad mencionados no Alcorão. É também qualificado como rasul e enviado por Deus para levar seu povo a seguir a mensagem da unidade.
} 
Nos ignorantes das realidades ou nos sábios.

É por isso que sua misericórdia abraça todas as coisas, As comuns e as de imenso valor"16.

A passagem corânica que trata da misericórdia universal de Deus é muito citada por Ibn'Arabi: Uwa rahmatî wasi'at kulla (Minha misericórdia abraça todas as coisas ${ }^{17}$ ). O rosto predileto de Deus, escolhido por Ibn'Arabî, é o do Deus amoroso, que estabelece uma aliança de amor com a humanidade e com toda a criação. É um Deus de amor que permite todas as audácias possíveis, que deseja um ardente enlace com os humanos e almeja com eles estabelecer sua morada ${ }^{18}$.

O coração purificado é capaz de perceber e captar as manifestações do Absoluto e acolher suas surpresas. Ele é o órgão sutil por excelência da captação das visões teofânicas, o "ponto de impacto dos acontecimentos espirituais", ou ainda "o órgão preparado por Deus para a contemplação"19. Trata-se do órgão que favorece o "verdadeiro conhecimento, a intuição compreensiva, a gnose (ma'rifa) de Deus e dos mistérios divinos" ${ }^{20}$. Num famoso hadith qudsî ${ }^{21}$ da tradição islâmica se diz: "Nem minha terra ou meu céu podem me conter, mas o coração do meu servo fiel me contém". O coração (qalb), enquanto órgão espiritual, está sempre em movimento e oscilação, refletindo a cada instante as diversas e inusitadas formas de manifestação do Absoluto. Na perspectiva mística ele vem compreendido como

\footnotetext{
${ }^{16}$ IBN'ARABÎ. Le livre des chatons des sagesses. Tome Premier. Beyrouth: Al-Bouraq, 1997, p. 265. ${ }^{17}$ Alcorão 7,156.

${ }^{18}$ Em seu livro sobre as teofanias, Ibn'Arabî expressa os desejos que movem o Deus de Amor com respeito às suas criaturas, como assinalado na bela tradução francesa de Ruspoli: "Je suis le Très-Beau, le Três-Gracieux. Alors aime-moi, mon bien aimé, aime-moi! N'aime que moi. Désire-moi, pense à moi, ne pense qu'à moi seul. Étreins-moi, enlace-moi, embrasse-moi (...). Demeure avec moi, tiens-tois près de moi. Ainsi je serai auprès de toi, tout comme tu es auprès de moi san même t'en rendre compte. La jonction! C'est la jonction qu'il nous faut!": Stéphane RUSPOLI. Le livre des théofanies d'Ibn Arabî. Paris: Cerf, 2000, p. 211 (Théophanie de la perfection, $\mathrm{n}^{\circ} 81$ ).

${ }^{19}$ Louis MASSIGNON. Écrits mémorables II. Paris: Robert Lafont, 2009, p. 309; Id. La passion de Husayn Ibn Mansûr Hallâj. Paris: Gallimard, 1975, p. 26.

${ }^{20}$ Henri CORBIN. L'immaginazione creatrice. Le radici del sufismo. Roma-Bari:Laterza, 2005, p. 193. O coração vem, assim, animado por uma função "teândrica", enquanto órgão mediante o qual "Deus conhece a si mesmo": Ibidem, p. 194. Segundo Ibn'Arabi, há no coração uma "cavidade secreta" que é o "ponto de contato com o Divino". Trata-se de um centro que é ele mesmo de natureza divina, facultando o exercício de sua função cognitiva: IBN'ARABÎ. Le livre des chatons des sagesses, p. 327 ( Tome Premier - comentário de Charles-André Gilis).

${ }^{21}$ Um dito atribuído ao profeta no qual Deus mesmo fala em primeira pessoa.
} 
taqallub a-qalb, ou seja, órgão em constante transformação. Como assinala Izutsu, "não existe limite nem fim à irradiação teofânica (tajallī) do Absoluto e que paralelamente as transformações internas (taqallub) do coração não têm limites, e isto significa que o conhecimento do Absoluto amplia-se incessantemente"'22. Em poema consagrado, Ibn'Arabî traduz essa plasticidade do coração, capaz de acolher todas as formas:

"Meu coração está aberto a todas as formas:

É uma pastagem para as gazelas,

E um claustro para os monges cristãos,

Um templo para os ídolos,

A Caaba do peregrino,

As tábuas da Torá,

E o livro do Corão.

Professor a religião do amor,

Em qualquer direção que avancem seus camelos;

A religião do amor

Será minha religião e minha fé" ${ }^{23}$.

Como indica Ibn'Arabî, o coração se alarga ou retrai para conformar-se à dinâmica da operação teofânica. O segredo dessa operação permanece, porém, misterioso para os humanos, que não conseguem abarcar o Mistério da Divindade Absoluta. Essa ninguém pode conter. Mas há um caminho de acesso que passa pelo domínio da profundidade, pelo centro do coração. Se o Mistério Absoluto não pode ser conhecido por si mesmo, ele pode ser acessado pelo mergulho na profundidade de $\mathrm{si}^{24}$. A mística francesa contemporânea, Simone Weil, captou isso de forma explêndida, ao indicar que somente "aquele que conhece o segredo dos corações", é capaz de alcançar "o segredo das diferentes formas de fé" 25 .

\footnotetext{
${ }^{22}$ Toshihiko IZUTSU. Unicità dell'esistenza e creazione perpetua nella mistica islâmica, p. 79 (e também pp. 76-77). O místico sufi Rûmî, também assinala essa dimensão de receptáculo protéico do coração: a cada instante atua, por força do Mistério, uma influência diferente no coração, uma nova marca, um desejo diferente, um abrasamento diferente. Cf. Djalâl-od-Dîn RÛMÎ. Mathnawî. La quête de l'absolu. Paris: Rocher, 1990, p. 630 (MIII: 1641-1644).

${ }^{23}$ IBN'ARABÎ. L'interprete delle passioni. Milano: Urra, 2008, p. 51 (XI, 13-15).

${ }^{24}$ Toshihiko IZUTSU. Sufismo e taoísmo. Milano: Mimesis, 2010, p. 61. E Ibn'Arabî baseia-se aqui num dito da tradição islâmica que assinala: "Man 'arafa nafsa-hu 'arafa rabba- hu ', ou seja, "Quem conhece si mesmo conhece o seu Senhor".

${ }^{25}$ Simone WEIL. Attente de Dieu. Paris: Fayard, 1966, p. 179.
} 
As diversas tradições religiosas são também canais de percepção do Mistério da Divindade. Elas traduzem crenças diversificadas e plurais. Mas Deus, enquanto Absoluto, não pode limitar-se a uma crença determinada. Sua Presença manifesta-se topicamente ali, mas não se esgota nessa tessitura temporal. As crenças são "como as inumeráveis cores que as pessoas impõem à luz incolor por meio de suas próprias existências delimitadas" 26 . É curioso notar que em árabe a palavra crença vem identificada com a expressão i'tiqâd, cuja raiz trilítera é 'QD, envolvendo os significados de atar, apertar com nós, unir etc. Ou seja, toda crença expressa um vínculo determinado, atando no tempo a percepção conjuntural do Mistério. Nesse sentido, as crenças "exigem pontos de vista delimitados e definidos que excluem outros pontos de vista. Na medida em que as pessoas aferram-se em suas crenças, provocam conflitos com as crenças dos outros" 27 . Na verdade, como mostra Ibn'Arabî, o conflito interreligioso ocorre em função do apego acirrado à "Divindade das conviç̧ões dogmáticas", que é a divindade feita à imagem e semelhança dos humanos, mas que é bem distinta da "Divindade Absoluta", que não pode ser limitada por crença alguma ${ }^{28}$. Ela "é capaz de assumir a forma de todas as crenças precisamente por ser incomparável a toda crença" ${ }^{29}$. No intuito de manter a saudável abertura interreligiosa, o shaikh lança uma importante advertência aos crentes:

"Cuide-se de não te ligar a um credo particular rejeitando todo o resto, pois perderás um bem imenso; além do mais, perderás a ciência da Verdade tal como é. Que tua alma seja a substância das formas de todas as crenças, pois Allah, o Altíssimo, é muito vasto e imenso para ser confinado num determinado credo, em exclusão dos outros. E Ele diz com efeito: Para onde quer que vos volteis, lá está a Face de Allah (...)"30.

\footnotetext{
${ }^{26}$ William C. CHITTICK. Mundos imaginales, p. 283.

${ }^{27}$ Ibidem, p. 276. De forma semelhante, o místico Rûmî assinala que o desacordo entre os seres humanos ocorre em razão do apego radical aos nomes, ao mundo da superfície das crenças. Se estivessem, ao contrário mais direcionados à profundidade do Mistério do Real, a paz seria alcançada: Djalâl-od-Dîn RÛMÎ. Mathnawî. La quête de l'absolu, p. 516 (MII: 3680).

${ }^{28}$ Para esta distinção cf. IBN 'ARABÎ. Le livre des chatons des sagesses. Tome second. Beyrouth: Al-Bouraq, 1998, p. 713 (em torno da profecia de Muhammad).

${ }^{29}$ William C. CHITTICK. Mundos imaginales, p. 280.

${ }^{30}$ IBN 'ARABÎ. Le livre des chatons des sagesses, p. 278 (Tome Premier). Trata-se da reflexão de Ibn 'Arabi a propósito de Hûd, considerado o "porta voz de todos os profetas".
} 
Ao contrário daqueles que si fixam no âmbito das ataduras, os gnósticos (arifun) conseguem ampliar o olhar e reconhecer a verdade que habita em toda crença, conscientes de que os nós existentes e plausíveis evidenciam uma delimitação da wujūd ilimitada. Os verdadeiros buscadores são animados pelo shaikh a ampliar suas crenças, "afim de desfrutar de uma maior 'participação ' $(h a z z)$ na visão do Real no outro mundo"31.

Só é capaz de uma tal abertura aquele que tem um coração receptivo, aberto para hospedar uma diversidade de formas e de atributos. É o que reconhece Ibn 'Arabî em seu Fusus, ao tratar da profecia de Schu'ayb. Os que são dotados de coração, não se confinam em seus credos particulares, mas buscam uma nova "síntese", onde permanecem receptivos aos dons gratuitos de Deus ${ }^{32}$. A abertura para uma tal perspectiva não significa ruptura com as formas tradicionais de exercício da crença particular. Como indica Ibn 'Arabî, o servidor perfeito equilibra o seu exercício de fé tradicional com a receptividade à "realização metafísica da Palavra". É alguém que reúne essas duas qualidades: o reconhecimento do rosto de Allah em suas obrigações rituais e convenções exteriores, bem como a abertura para a "contemplação de Deus em todas as direções" 33 .

Não há dúvida de que Ibn 'Arabi foi um dos mais importantes místicos na abertura para uma perspectiva interreligiosa. Vem reconhecido por Chittick como "o pensador mais complexo e profundo" na defesa de um pluralismo religioso $^{34}$. A diversidade religiosa era vista por ele como um dos muitos sinais da infinita misericórdia de Deus. O toque de seu discurso não é o de um simples acadêmico, mas de um "conhecedor" ('ârif), no sentido nobre da palavra. Ele diz, repetidamente, como lembra Chittick, "que nunca fala por si mesmo, que nunca escreve por sua própria volição. Sempre, ele diz, é a Haqq divina que está falando através dele e o forçando a colocar no papel o que está sendo revelado dentro do seu coração. É a Haqq divina que está realizando o processo de tahqîq (realização) através dele"35. Num trecho do capítulo 54 de sua grandiosa obra, Al-futuhat al-makkiyya (As revelações de Meca),

${ }^{31}$ William C. CHITTICK. Mundos imaginales, p. 282.

${ }^{32}$ IBN 'ARABÎ. Le livre des chatons des sagesses, pp. 318-319 (Tome Premier).

${ }^{33}$ Ibidem, pp. 279 e 291 (Hûd). Ver ainda: Cecília TWINCH. El círculo inclusivo. In: Pablo BENEITO \& Pilar GARRIDO (Eds). El viaje interior entre Oriente y Occidente. La actualidad del pensamiento de Ibn'Arabî. Madrid: Alquitara, 2007, pp. 60-72.

${ }^{34}$ William C. CHITTICK. Mundos imaginales, p. 10.

${ }^{35}$ William CHITTICK. Ibn'Arabi e Rûmî, p. 35. 
ele faz a distinção entre o conhecimento recebido dos mortos e o conhecimento recebido do eternamente vivo. O primeiro é o que traduz o conhecimento do erudito exotérico, cujo saber procede dos mortais e o segundo, do possuidor do verdadeiro conhecimento, que procede do "Vivente, aquele que não morre" (al-Bistami) ${ }^{36}$.

\section{Referências Bibliográficas}

BENEITO, Pablo \& GARRIDO, Pilar (Eds). El viaje interior entre Oriente $y$ Occidente. La actualidad del pensamiento de Ibn'Arabi. Madrid: Alquitara, 2007.

CHITTICK, William C. Mundos imaginales. Ibn'Arabi y la diversidad de las creencias. Sevilla: Alquitara, 2003.

CHITTICK, William C. Il sufismo. Torino: Einaldi, 2009.

CHITTICK, William C. Ibn'Arabi e Rûmî. Numen, v. 8, n. 1, 2005, pp. 23-37.

CORBIN, Henri. L'immaginazione creatrice. Le radice del sufismo. RomaBari: Laterza, 2005.

HIRTENSTEIN, Stephen. O compassivo ilimitado. A vida e o pensamento espiritual de Ibn 'Arabi. Rio de Janeiro: Fissus, 2006.

IBN 'ARABI. Le livre des chatons des sagesse. Tome Premier. Beyrout: Al-Bouraq, 1997.

IBN 'ARABI. Le livre des chatons des sagesse. Tome Second. Beyrout: Al-Bouraq, 1998.

IBN 'ARABI. L'interprete delle passione. Milano: Urra, 2008.

ISUTZU, Toshihiko. Unicità dell'esistenza e creazione perpetua nella mistica islâmica. Genova: Marietti, 1991.

ISUTZU, Toshihiko. Sufismo y taoísmo. 2 ed. Madrid: Siruella, 2004.

MASSIGNON, Louis. Essais sur les origines du lexique technique de la mystique musulmane. Paris: Cerf, 1999.

MASSIGNON, Louis. Écrits memorables 1. Paris: Robert Lafont, 2009.

MASSIGNON, Louis. Écrits memorables 2. Paris: Robert Lafont, 2009.

MOLÉ, Marijan. I mistici musulmani. Milano: Adelphi, 1992.

RÛMÎ, Djalâl-od-Din. Mathnawî. La quête de l'Absolu. Paris: Rocher, 1990.

\footnotetext{
${ }^{36}$ Apud Pablo BENEITO ARIAS. Esoterismo diante do exoterismo: a linguagem das alusões no sufismo segundo Ibn'Arabî de Múrcia. In: Faustino TEIXEIRA (Org.). No limiar do mistério, 391-392.
} 
RUSPOLI, Sthéphane. Le livre des théophanies d'Ibn Arabî. Paris: Cerf, 2000. SELLS, Michael. Tres seguidores de la religión del amor: Nizãm, Ibn'Arabi y Marguerite Porete. In: BENEITO, Pablo \& PIERA, Lorenzo \& BARCENILLA, Juan Jose (Eds). Mujeres de luz. Madrid: Trotta, 2011, pp. 137-155.

TEIXEIRA, Faustino (Org.). No limiar do mistério. São Paulo: Paulinas, 2004. WEIL, Simone. Attente de Dieu. Paris: Fayard, 1966.

\section{Faustino Teixeira}

Doutor em Teologia pela Pontifícia Universidade Gregoriana de Roma (1985), com Pós-Doutorado na mesma Universidade (1998). Professor do Programa de Pós-Graduação em Ciência da Religião da Universidade Federal de Juiz de Fora. Pesquisador do CNPq e Consultor do Iser-Assessoria.

Artigo Recebido em 04/10/2011

Artigo Aprovado em 29/11/2011 